\title{
A diagnostic tool for assessing the conservation condition of cellulose nitrate and acetate in heritage collections: quantifying the degree of substitution by infrared spectroscopy
}

Sofia Nunes ${ }^{1}$, Francesca Ramacciotti ${ }^{2}$, Artur Neves ${ }^{1}$, Eva Marisole Angelin ${ }^{1}$, Ana Maria Ramos ${ }^{1}$, Élia Roldão ${ }^{1}$, Nadja Wallaszkovits ${ }^{3}$, Alfonso Alejo Armijo ${ }^{1}$ and Maria João Melo ${ }^{1 *}$

\begin{abstract}
Cellulose nitrate and acetate are materials at risk in heritage collections because it is not possible to predict the evolution of their conservation state over time. Knowing that the degree of substitution (DS) of these materials correlates with their state of conservation because the fundamental degradation mechanism is hydrolysis, in this work, DS was measured in historical objects and artworks. Infrared spectra were used to develop and optimize calibration curves for cellulose nitrate and acetate references that were next applied to calculate DS values of heritage objects. The extent of hydrolysis measured, with this tool, correlated well with the physical deterioration assessed through the sample hardness (Shore A) which was measured with a Durometer. Calibration curves were optimized in reference materials by Attenuated Total Reflectance (ATR-FTIR) and Micro Fourier Transform Infrared Spectroscopy ( $\mu$ FTIR). The DS values of the AC reference materials was previously calculated by nuclear magnetic resonance spectroscopy. The calibration curves were obtained plotting DS as a function of the ratio between a reference peak (which does not suffer relevant changes during degradation) and selected peaks that monitor the degradation for cellulose acetate and nitrate polymers (avoiding the interference of plasticizers). The reference peak for both was the COC stretching mode (VCOC). The probe peak was, for cellulose nitrate, the $\mathrm{NO}_{2}$ asymmetric stretching $\left(\mathrm{V}_{\mathrm{a}} \mathrm{NO}_{2}\right)$ and, for cellulose acetate, the $\mathrm{OH}$ stretching mode $(\mathrm{VOH})$. This ratio was then applied to calculate DS values of historical materials, in good and poor conservation condition; in situ by ATR, and in micro-samples collected from artworks by $\mu$ FTIR. This selection comprises cinematographic and photographic films dated from the 1890s to the 1960s, and contemporary works of art made with cellulose acetate sheets by Portuguese artist José Escada dated from the 1960s. Finally, by comparison with the original estimated DS values, we show how this tool permits to define the state of degradation of these complex polymer matrixes. Thus, establishing the quantification of the DS as a novel tool to monitor the degradation of cellulose ester plastics, contributing in this way for a sustainable preservation of an irreplaceable heritage.
\end{abstract}

Keywords: Cellulose nitrate, Cellulose acetate, Modern materials, Heritage collections, Conservation, Degradation mechanisms, Infrared spectroscopy

\footnotetext{
*Correspondence: mjm@fct.unl.pt

1 REQUIMTE-Laboratório Associado para a Química Verde, Departamento

de Química e Departamento de Conservação e Restauro, Faculdade de Ciências e Tecnologia, Universidade NOVA de Lisboa, 2829-516 Caparica, Portugal

Full list of author information is available at the end of the article
} adaptation, distribution and reproduction in any medium or format, as long as you give appropriate credit to the original author(s) and the source, provide a link to the Creative Commons licence, and indicate if changes were made. The images or other third party material in this article are included in the article's Creative Commons licence, unless indicated otherwise in a credit line to the material. If material is not included in the article's Creative Commons licence and your intended use is not permitted by statutory regulation or exceeds the permitted use, you will need to obtain permission directly from the copyright holder. To view a copy of this licence, visit http://creativeco mmons.org/licenses/by/4.0/. The Creative Commons Public Domain Dedication waiver (http://creativecommons.org/publicdomain/ zero/1.0/) applies to the data made available in this article, unless otherwise stated in a credit line to the data. 


\section{Introduction}

A vast percentage of European cultural heritage can be found in cinematographic films and photography produced since 1899 [1-5]. Images are obtained through a complex stratigraphy that is depicted in Scheme 1 [6]. The base for these images is made of cellulose derivatives, which depending on their history of manufacture, storage and use may reveal a high degree of instability [1-5]. For this reason, more than 120 years of visual memories, based on cellulose nitrate $(\mathrm{CN})$ and cellulose acetate $(\mathrm{CA})$ materials, are in danger to be lost [1-5]. To overcome this risk, the European project NEMOSINE aims at improving the traditional storage solutions based on cold storage, by developing a modular package with the main goal of energy-saving and extent conservation time (https:// nemosineproject.eu). This innovative package is based on an in-depth knowledge of the fundamental mechanisms of degradation and, on the continuous monitoring of volatiles which correlates with the conservation state of the support, Additional file 1: Scheme S1.

Knowing that hydrolysis is the fundamental degradation mechanism for both materials, the conservation condition of these supports may be correlated to their degree of substitution. For this reason, in this work, we conceive a tool to measure the degree of substitution ${ }^{1}$ (DS) of $\mathrm{CN}$ and CA in historical films (photographic and cinematographic) and contemporary artworks. As it was shown that infrared spectroscopy is a powerful tool to calculate DS in cellulose acetate [7], calibration curves were based on infrared spectral data. In the field of cultural heritage, this technique may be applied in situ by Attenuated Total Reflection-Fourier Transform Infrared Spectroscopy (ATR-FTIR), or in microsamples weighing less than $0.1 \mu \mathrm{g}$ by Micro Fourier Transform Infrared Spectroscopy ( $\mu$ FTIR). For the case studies in which it is possible to predict, with some confidence, the initial (original) degree of substitution, the calculated DS allows to quantify the degradation extent, Table 1. The extent of hydrolysis measured is compared with the physical deterioration assessed through the sample hardness (Shore A) which was measured with a Durometer.

Next, the state of the art for the degradation mechanisms at play in cellulose nitrate and acetate is briefly summarized, showing how DS relates with it; a brief historical overview is also provided, in which the most common plasticizers are described in context, as they are important in the degradation mechanisms and are also detected in the infrared spectra.

\footnotetext{
${ }^{1}$ The degree of substitution (DS) of a polymer is the (average) number of substituent groups attached per monomeric unit. The term has been used mainly in cellulose chemistry where each anhydroglucose ( $\beta$-glucopyranose) unit has three reactive (hydroxyl) groups; degrees of substitution may therefore range from zero (cellulose itself) to three (fully substituted cellulose).
}

\section{Manufacture of cellulose nitrate and acetate and description of their most common plasticizers}

In the 1870s, John Wesley Hyatt developed the first commercially successful semisynthetic plastic-celluloidby applying heat and pressure to a mixture of cellulose nitrate and camphor (a typical formulation could consist in the use of $30 \%$ of camphor). Celluloid's flexibility, dimensional stability, and transparency eventually led to its extensive use as a new photographic and cinematographic medium for films, as a result of the developments of Eastman Kodak and Henry Reichenbach in 1888-1889 [8]. Later camphor began to be replaced by other plasticizers, namely triphenyl and tricresyl phosphates, after 1902 , and by phthalates in the 1920s $[9,10]$. As support for image, cellulose nitrate was widely used between the 1890 s and 1950s, but due to its inflammability, it was gradually substituted by cellulose acetate films. Its replacement started around 1904 with the commercialization of cellulose diacetate and was fully achieved in the 1950s with the large-scale manufacture of cellulose triacetate [11]. The main plasticizers used in cellulose acetate were triphenyl phosphate (TPP) and diethyl phthalate (DEP) in $20-40 \%$ by weight [12]. Recent research carried out at the Getty Conservation Institute as evidenced that plasticizer loss, in artificially aged CA samples, induced a lower ability to keep flexibility because hardness increases and, consequently, materials are more vulnerable to physical damage [10].

\section{Degradation mechanisms for cellulose nitrate}

For cellulose nitrate, experimental evidence has shown that mechanisms based on radical propagation are dominant [13-15]. Allen et al. $[4,16,17]$, on their pioneer studies with artificially aged and historical CA and CN $35 \mathrm{~mm}$ films from the National Film and Television Archive (United Kingdom), established that moisture absorption together with the accumulation of acid in the storage cans is the most important cause in film degradation. They concluded that the effect of temperature accelerates degradation in moist or acid environments and that in dry conditions degradation occurs at a very slow rate [16].

It has been proved that $\mathrm{CN}$ degradation occurs stepwise through side and main chain scission [13-15, 18-21]. The first phase is characterized by the homolytic cleavage of the RO- $\mathrm{NO}_{2}$ bond in $\mathrm{C} 2$ or $\mathrm{C} 3$, forming an alkoxy radical ( $\mathrm{RO}^{*}$ ) and releasing a $\mathrm{NO}_{2}{ }^{\circ}$, Scheme 2 . The $\mathrm{NO}_{2}{ }^{\circ}$ radical can be transformed into the pair $\mathrm{HNO}_{2} / \mathrm{HNO}_{3}$ by hydrogen abstraction and reaction with $\mathrm{H}_{2} \mathrm{O}[20,22]$. Over time, a complete loss of the nitrate substitution in the cellulose ring is observed, leading to a decrease of the degree of substitution (through the formation of hydroxyl groups), Scheme 2. 


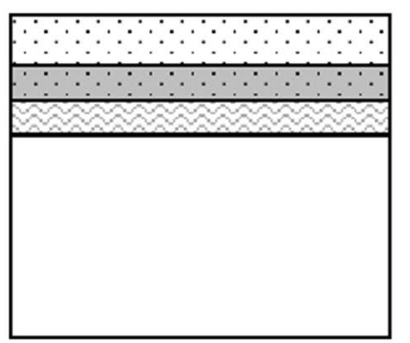

Emulsion layer (silver colloids dispersed in a proteinaceous matrix)

Anti-halation layer (anti-halation dyes in a proteinaceous matrix)

Subbing layer (mixture of cellulose nitrate or acetate and protein)

\section{Support in cellulose nitrate or acetate}

Scheme 1 General structure of a black and white cinematographic film. The cellulose nitrate or acetate base is the thickest layer and it is the support of the image. The image is formed by silver colloids dispersed in a proteinaceous matrix which is adhered to the support, usually, by a layer of protein-based gelatin and cellulose nitrate or acetate (subbing layer). The anti-halation layer is a proteinaceous matrix with anti-halation dyes (e.g., acid fuchsin or malachite green) that prevents light to be reflected in the emulsion causing a halo effect

Table 1 Applications of cellulose nitrate/cellulose acetate according to the nitrogen content/acetyl content and the degree of substitution (DS) [30,34]

\begin{tabular}{llll}
\hline Polymer & Applications & $\begin{array}{l}\text { Nitrogen/ } \\
\text { acetyl } \\
\text { content (\%) }\end{array}$ & $\begin{array}{l}\text { Degree } \\
\text { of substitution }\end{array}$ \\
\hline Cellulose nitrate \\
& Explosives & $12-13.5$ & $2.26-2.76$ \\
& Adhesives & 12 & 2.26 \\
& Film base & 12 & 2.26 \\
& Lacquers, coatings & $11.2-12$ & $2.02-2.26$ \\
& Plastics & $10.5-11.2$ & $1.83-2.02$ \\
Cellulose acetate & Injection molding & $52.1-54.3$ & $2.2-2.3$ \\
& Film & $54.3-56.4$ & $2.3-2.4$ \\
& Lacquers & $56.4-59.3$ & $2.4-2.6$ \\
& Film and fiber & $60.7-62.85$ & $2.9-3.0$ \\
\hline
\end{tabular}

a Values in italic were used for our case studies: cinematographic films and photographic negatives. In the case of the artworks from José Escada, the injection molding values were considered as the original DS

b The degree of substitution can be calculated from the nitrogen and acetyl contents (\%) by the following equations $[12,35]$ : DS $=\frac{3.60 \times(\% \text { nitrogen })}{31.13-(\% \text { itrogen })}$; $\mathrm{DS}=162 \times\left(\frac{3.86 \times(\% \text { acetyl })}{102.4-(\% \text { acetyl })}\right)$

In phase two, main chain scission starts by the formation of hydroperoxides at $\mathrm{C} 1$ and their decomposition promotes a continuous cleavage of the glycosidic linkages and formation of carbonyl intermediates-the gluconolactones, identified at $1735-1740 \mathrm{~cm}^{-1}$ in the infrared spectrum by Berthumeyrie et al. [15]. Another possible mechanism for main chain scission is the acid-catalyzed scission of the glycosidic bonds, induced by the presence of moisture and continuous formation of $\mathrm{HNO}_{2}$ and $\mathrm{HNO}_{3}$ [20].

\section{Degradation mechanisms for cellulose acetate}

According to the literature [20, 23, 24], heterolytic bond cleavage prevails in cellulose acetate degradation mechanism catalyzed by acids; it occurs by: (i) side chain scission through ester hydrolysis, with formation of a hydroxyl group and release of acetic acid, Scheme 2, and (ii) main chain scission by cleavage of the glycosidic bonds, Additional file 1: Scheme S2.

Although homolytic scission is not considered in archival conditions as the main degradation mechanism, photooxidation studies provide insights on radical chain reactions that can occur in the polymer matrix, as described for cellulose nitrate. In the absence of $\mathrm{O}_{2}$ and irradiating at $\lambda \geq 235,280$ and $340 \mathrm{~nm}$, Hon [25], Merlin and Fouassier [26] demonstrated that the formation of $\mathrm{CH}_{3}{ }^{\cdot}$ and $\mathrm{H}^{*}$ abstraction promotes chain scission. $\mathrm{CH}_{4}$, $\mathrm{CO}$, and $\mathrm{CO}_{2}$ were experimentally identified as the main volatiles irradiating at $\lambda \geq 235$ and $280\left(\mathrm{CH}_{3} \mathrm{COOH}\right.$ was only detected for $\lambda_{\text {irr }} \geq 280 \mathrm{~nm}$ ) (Additional file 1: Scheme S3). Irradiating at $\lambda \geq 275 \mathrm{~nm}$ cellulose acetate inside glass vials, Hosono et al. observed that photooxidation, leading to main chain scission, only occurs in the presence of photosensitizers through the formation of hydroperoxides [27].

\section{Calibration curves to measure the degree of substitution of CA based on infrared spectra}

To calculate cellulose acetate degree of substitution, Fei et al. [7] prepared calibration curves by admixing commercial powders of cellulose triacetate and microcrystalline cellulose (in $\mathrm{KBr}$ pellets). They observed that a $2^{\text {nd }}$ degree polynomial regression of the data had higher coefficients of determination, giving the following explanation for the non-linear relationship between the degree of substitution and the chosen ratios at high degrees of acetylation (DS > 1.8): "With increased acetyl groups in the system of CA with a higher DS value the molar absorptivity starts to change from a linear relationship to a non-linear relationship due to the changing charge distribution at decreased average distances between particles or groups." Before Fei et al. study, Samios et al. [28] obtained a linear calibration curve to calculate the degree of substitution for DS values below 2.5. Thus, for DS values bellow 2.5, it is possible to use a linear calibration fitting with a high coefficient of determination. 


\section{Cellulose Nitrate homolytic side-chain scission}

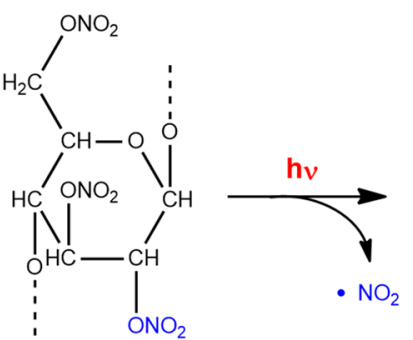

DS 3

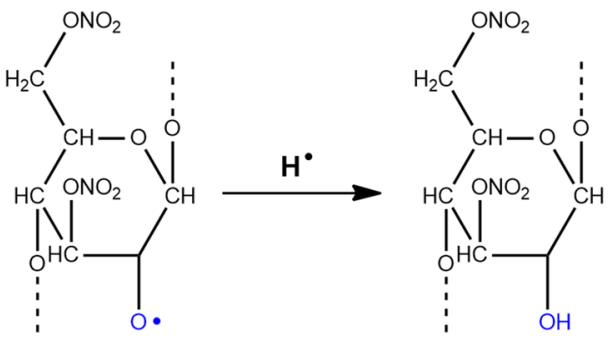

DS 2

\section{Cellulose Acetate heterolytic side-chain scission}
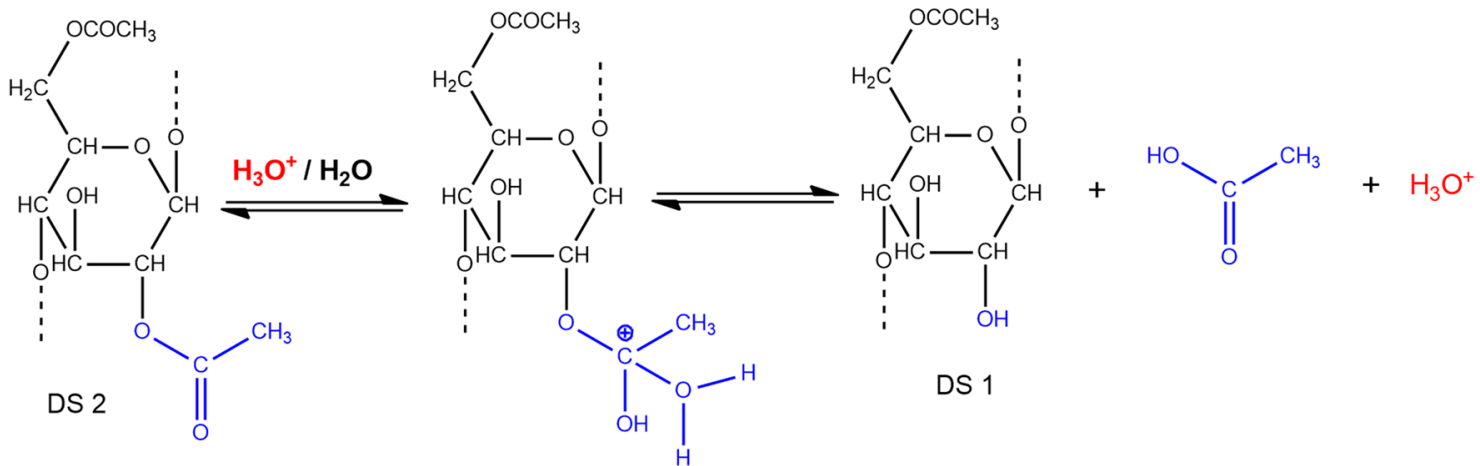

Scheme 2 Cellulose nitrate degradation occurs by the homolytic scission of the nitrate groups resulting in the release of $\mathrm{NO}_{2}{ }^{\circ}$ and the formation of an alkoxy radical. By the addition of $\mathrm{H}^{\circ}$, the alkoxy radical is transformed into a hydroxyl, resulting in the decrease of the DS, top. The acid-catalyzed heterolytic side-chain scission of the acetyl esters occurs by nucleophilic substitution, with the release of acetic acid and formation of a hydroxyl group, which also results in the decrease of the DS, bottom

\section{Aims of this research}

In the heritage field, attempts made to use FTIR to measure deacetylation of CA polymers based on the hydroxyl to carbonyl peak area proved unsatisfactory [12]. On the other hand, gas chromatography/mass spectrometry provided an accurate quantification, after removal of the plasticizers by solvent extraction. A major drawback of this technique is that it requires $0.3-0.9 \mathrm{mg}$ samples, which will be extremely difficult to access in heritage objects [12]. For this reason, we propose to further explore infrared spectroscopy, as it may be applied in situ or in microsamples with weights bellow 0.1 micrograms.

In this work, the calculation of the degree of substitution will be first optimized on $\mathrm{CN}$ and $\mathrm{AC}$ reference samples using the approach developed by Fei et al. [7]. However, contrary to these authors, infrared spectra are collected directly in reference materials and historical artworks: (i) in situ by Attenuated Total Reflection-Fourier Transform Infrared Spectroscopy (ATR-FTIR), and (ii) in micro samples by Micro Fourier Transform Infrared Spectroscopy ( $\mu$ FTIR).

Accurate DS values for the cellulose acetate reference materials were obtained by nuclear magnetic resonance spectroscopy (NMR) applying the quantitative method described by Kono et al. [29]. For cellulose nitrate reference material, DS was based on Berthumeyrie et al. quantitative elemental analysis [15]. Work is currently in progress to develop a method to calculate DS values by NMR.

The optimized calibration curves obtained for CA and $\mathrm{CN}$ are tested to calculate the DS in several heritage objects, as follows: (i) photographic films in good conservation condition, from the San Payo collection, studied in Roldão's Ph.D. project [30]; (ii) cinematographic films that are used in the NEMOSINE project, displaying diverse conservation conditions; (iii) cinematographic films from the National Archive of Motion Pictures (ANIM) in a severe state of degradation; (iv) three similar Portuguese artworks from José Escada with, visually, different states of degradation. 
To the best of our knowledge, this will be the first time that this type of calibration curves will be employed for the quantification of cellulose nitrate degree of substitution, and for assessing the degree of degradation of CA and $\mathrm{CN}$ historical matrixes.

\section{Experimental}

\section{Description of the historical samples}

A preliminary analysis by $\mu$ FTIR allowed the identification of the support material and of the plasticizer class (see Additional file 1).

\section{Cinematographic Films from NEMOSINE project}

Cinematographic films from the Phonogrammarchiv of the Vienna Academy of Sciences (OEAW, Austria) and Deutsches Filminstitut \& Filmmuseum (DFF, Frankfurt, Germany) were studied. Information about sample denomination, date and typology were given by the archive and are described in Additional file 1: Table S1. The thickness was measured with a micrometer in three points of each film and the average values are presented.

\section{Cinematographic Films from the National Archive of Motion Pictures (ANIM)}

$35 \mathrm{~mm}$ cellulose nitrate cinematographic films were obtained from an aluminum can of the National Archive of Motion Pictures (ANIM, Portugal) labeled as belonging to the film Man Are That Way (1939), by director Arthur Maria Rabenault. Within the aluminum box, there are several reels of which the provenances are not known. The archive of the Portuguese national cinematheque was created in 1948 and in 1996 the conservation center, known as ANIM, was built. It is known from the literature that these films were widely used between the 1890s and the 1950s and that the production ceased in 1951 due to cellulose nitrate flammability. Therefore, these films can date from 1948 to 1951 or earlier. The films present inside are in an advanced stage of degradation, with tacky emulsion, loss of image and intense noxious smell. These films have already been studied in a published work by infrared and Raman spectroscopies [31].

\section{San Payo collection}

The samples analyzed belong to the Portuguese collection San Payo. Through Élia Roldão macro and molecular assessment, the samples selected are in a good state of conservation. The macro assessment consisted in the visual and olfactive identification of deterioration signs and the molecular assessment in $\mathrm{pH}$, hardness (Shore A) and FTIR measurements [30].

\section{Reliefs from José Escada}

Three Portuguese artworks on cellulose acetate (CA) by the artist José Escada dated from the 1960s. They are all compositions of symmetric modules in CA sheets that have been folded and cut in different shapes creating a three-dimensional effect. These modules are supported by a sheet of the same material and a wooden grid or a panel. Relief orange, from 1966, currently in the Conservation and Restoration Department of FCT NOVA (Caparica, Portugal) presents warping, shrinkage, and hardening of the plastic material. La fête, from 1967, belongs to Galeria 111 (Lisbon, Portugal) and is currently in the Conservation and Restoration Department of FCT NOVA (Caparica, Portugal). This last artwork presents an advanced stage of degradation, showing, beyond the signs of Relief orange, detachment of the modules and loss of the material. Dans la plage, from 1968, currently in the National Museum of Contemporary Art (Lisbon, Portugal) does not show signs of degradation like the other two.

\section{Materials and methods}

Cellulose diacetate powder (Sigma-Aldrich, 39.7 wt\% acetyl content), cellulose triacetate purum (Fluka), cellulose nitrate membranes (Hybond ${ }^{\mathrm{TM}} \mathrm{ECL}^{\mathrm{TM}}$, GE Healthcare), microcrystalline cellulose powder (Sigma-Aldrich), racemic camphor (Fragon 33069-27, $\mathrm{C}_{10} \mathrm{H}_{16} \mathrm{O}$ ), triphenyl phosphate (Sigma-Aldrich, $\geq 99 \%$ ), diethyl phthalate (Alfa Aesar, 99\%) were used as powders; or, dissolved in methanol (HPLC grade), dichloromethane (organic trace analysis, $\geq 99.9 \%)$ and acetone $(\geq 99.9 \%)$ were used. DMSO- $d_{6}$ was used for NMR studies.

\section{Cellulose acetate solutions for NMR}

Cellulose acetate samples (20-25 mg) were dissolved in $500 \mu \mathrm{L}$ of DMSO- $d_{6}$. The DS of commercial cellulose acetate samples was measured by integration method of ${ }^{1} \mathrm{H}$ NMR and ${ }^{13} \mathrm{C}$ NMR signals (see Additional file 1: Figures $\mathrm{S} 1, \mathrm{~S} 2, \mathrm{~S} 3$, and S4).

\section{Preparation of samples with different degrees of substitution} Based on the work of Fei et al. samples with different degrees of substitution were obtained by co-grinding appropriate amounts of commercial powders of microcrystalline cellulose (MCC, DS 0 ) and cellulose diacetate (CDA). Commercial cellulose triacetate (CTA) was used as reference for the value DS 2.97. The relationship between the DS and the masses is described by Eq. 1:

$$
D S(\text { Degree of substitution })=\frac{m_{C D A} / M_{C D A} \times D S_{C D A}}{m_{C D A} / M_{C D A}+m_{M C C} / M_{M C C}}
$$

Equation 1 Relationship between DS and MCC and CDA masses. Where: $m_{C D A}$ and $m_{M C C}$ are the masses of CDA 
and $\mathrm{MCC}$ in the mixture, $\mathrm{M}_{\mathrm{CDA}}\left(264.48 \mathrm{~g} \mathrm{~mol}^{-1}\right)$ and $\mathrm{M}_{\mathrm{MCC}}\left(162 \mathrm{~g} \mathrm{~mol}^{-1}\right)$ are the average molecular mass $\left(\mathrm{g} \mathrm{mol}^{-1}\right)$ repeating units and $\mathrm{DS}_{\mathrm{CDA}}$ is the degree of substitution of commercial CDA (DS 2.32).

The DS prepared by grinding MCC with CDA were $0.48 ; 0.95 ; 1.43$; and 1.90 . The relative mass of MCC and CDA measured for sample preparation were calculated with Eq. 2 obtained by solving Eq. 1 as follows.

$$
\frac{m_{C D A}}{m_{M C C}}=\frac{264.48 \mathrm{~g} \mathrm{~mol}^{-1} \times D S}{162 \mathrm{~g} \mathrm{~mol}^{-1} \times 2.32-162 \mathrm{~g} \mathrm{~mol}^{-1} \times D S}
$$

Equation 2 Relationship between the DS and the mass ratio of cellulose diacetate and microcrystalline cellulose in the mixture.

The powders were ground with a mortar and pestle with the addition of droplets of water, when necessary. The mixtures obtained were put in a desiccator overnight before being analyzed.

To obtain a powder of cellulose nitrate $(\mathrm{CN})$, commercial filtration membranes (GE Healthcare) were cut with scissors and scalpels. To reduce particle size, the cut membranes were sieved. The relative amounts of MCC and $\mathrm{CN}$ powders have been calculated by adaptation of Eq. 2 (where $261 \mathrm{~g} \mathrm{~mol}^{-1}$ and $162 \mathrm{~g} \mathrm{~mol}^{-1}$ are the average mass of $\mathrm{CN}$ and $\mathrm{MCC}$, respectively and 2.2 the DS of the commercial membranes.) The standards used for the calibration curve have been prepared with DS: $0.5 ; 1.0 ; 1.5$ and 2.0. The powders were ground with a mortar and pestle with the addition of droplets of water, when necessary. The mixtures obtained were kept in a desiccator overnight before being analyzed. The total mass of each mixture was approximately $6.0 \mathrm{mg}$ for both $\mathrm{CA}$ and $\mathrm{CN}$.

\section{The making of the calibration curves}

The absorbance intensities of the chosen probe and reference peaks for the ratio calculation were measured using OMNIC software. Following Fei et al. methodology, baselines were delineated using the peak height tool and the absorbance calculated from the maximum of the characteristic peak to the corresponding baseline. For $\mu$ FTIR, the probe $\left(v_{\mathrm{a}} \mathrm{NO}_{2}, \mathrm{~A}_{1653 \mathrm{~cm}^{-1}}\right)$ and reference

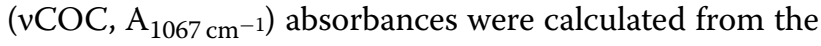
maximum to the baseline delineated between the points at 2000 and $1570 \mathrm{~cm}^{-1}$ and at 1570 and $940 \mathrm{~cm}^{-1}$. For ATR-FTIR, the probe $\left(v_{\mathrm{a}} \mathrm{NO}_{2}, \mathrm{~A}_{1636 \mathrm{~cm}^{-1}}\right)$ and reference

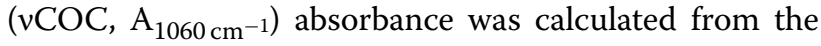
maximum to the baseline delineated between the points at 1800 and $1525 \mathrm{~cm}^{-1}$ and at 1190 and $930 \mathrm{~cm}^{-1}$. For the DS calibration curves, for each DS, 3 spectra were used for $\mu$ FTIR and 5 spectra for ATR-FTIR. The linear and polynomial ( $2^{\text {nd }}$ degree) regressions of the data were calculated using OriginPro 8.

\section{Equipment}

Nuclear magnetic resonance spectroscopy

NMR spectra were run at $353 \mathrm{~K}$ on an ASCEND 500 spectrometer $\left(500 \mathrm{MHz}\right.$ for $\left.{ }^{1} \mathrm{H}\right)$ equipped with a Cryoprobe, ATM, Prodigy TCI 500 at $353 \mathrm{~K}$.

\section{Micro Fourier Transform Infrared Spectroscopy ( $\mu$ FTIR)}

Infrared spectra were acquired on a Nicolet Nexus spectrophotometer equipped with a Nicolet Continu $\mu$ m (15× objective) microscope and a Mercury-CadmiumTellurium (MCT) detector cooled by liquid nitrogen. $\mu$-samples were placed on a diamond cell and the spectra were acquired in transmission mode between the $4000-650 \mathrm{~cm}^{-1}$, with a resolution of $8 \mathrm{~cm}^{-1}$ and 128 scans. $\mu$-samples from the selected case studies were collected using Ted Pella $\mu$-tools and a Leica MZ16 stereomicroscope (between $7.1 \times$ and $115 \times$ ), equipped with a Leica ICD digital camera and a Leica KI fiber optic light system 1500LCD. Spectra are shown here as acquired, without corrections or any further manipulation, except for the removal of the $\mathrm{CO}_{2}$ absorption at approximately $2300-2400 \mathrm{~cm}^{-1}$.

\section{Attenuated Total Reflectance (ATR-FTIR)}

The spectra were obtained by an Agilent Handheld Exoscan 4300 spectrophotometer equipped with a wire-wound source and DTGS detector in the $4500-650 \mathrm{~cm}^{-1}$ spectral region. ATR spectra were obtained in reflectance mode with a resolution of $8 \mathrm{~cm}^{-1}$ and 64 scans. The samples were analyzed in situ without prior treatments.

\section{Hardness measurement}

Sample hardness (Shore A) was measured with an HP Durometer (model HPSA, from Checkline Europe), with a scale from 0 to 100 . For each sample, the hardness values and standard deviation were determined as the average of five independent measurements obtained in a film area of ca. $35 \mathrm{~mm} \times 35 \mathrm{~mm}$. The sample was placed always in the same flat surface, and the measurements were made in the middle and near the corners.

\section{Results and discussion}

DS values calculated for cellulose acetate references by NMR

The DS of commercial cellulose acetate samples was measured by integration method using ${ }^{1} \mathrm{H}$ NMR and quantitative ${ }^{13} \mathrm{C}$ NMR (see Additional file 1). Briefly, quantification of the number of acetyl groups present in the sample could be achieved by ${ }^{1} \mathrm{H}$ NMR by comparison between the area of methyl group signals between 2.08 and $1.90 \mathrm{ppm}$ and the area of ring proton signals between 5.06 and $3.46 \mathrm{ppm}$. The results agreed with what obtained by quantitative ${ }^{13} \mathrm{C} \mathrm{NMR}$, by comparison between the 


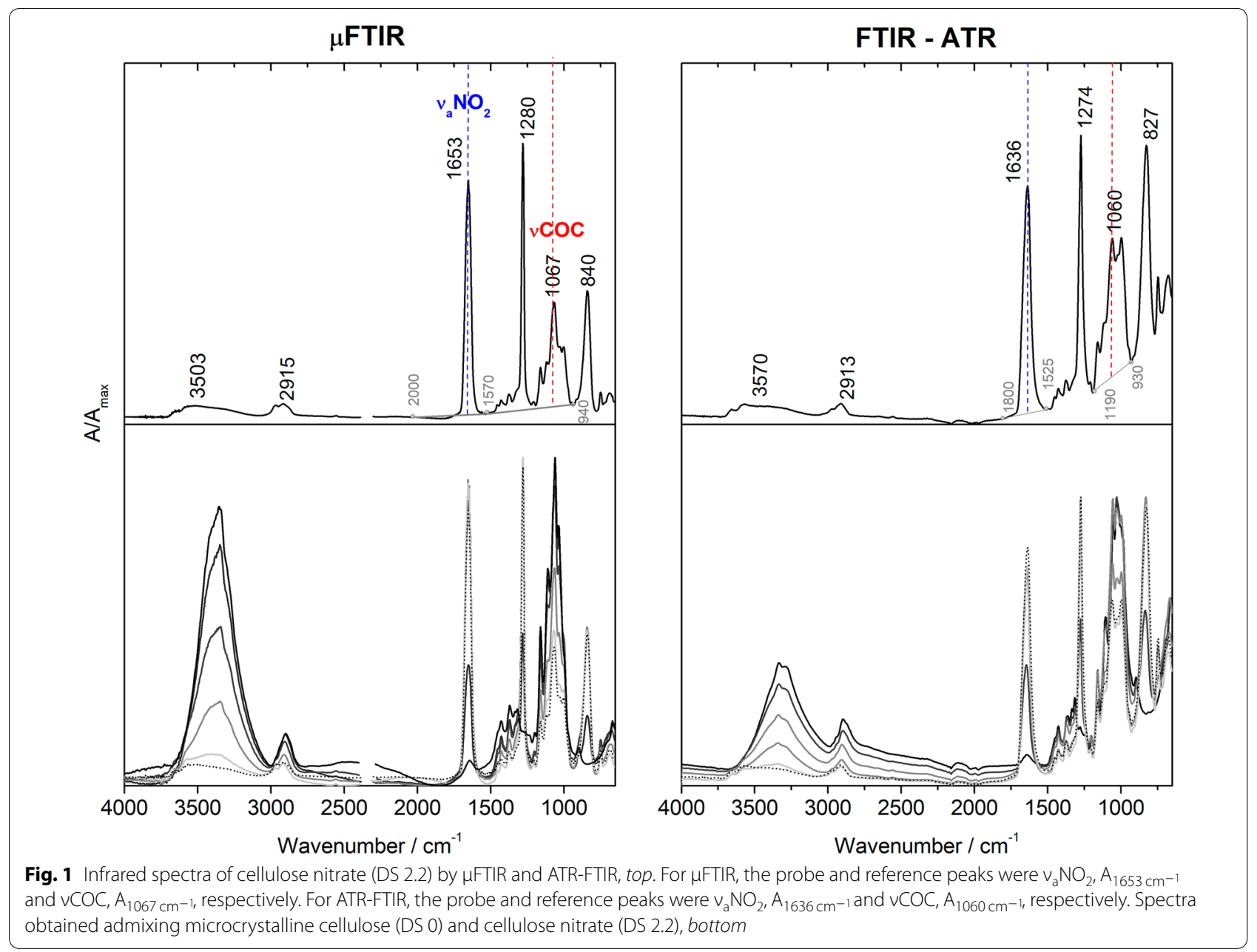

area of carbonyl group (around $170 \mathrm{ppm}$ ) or methyl group (around $20 \mathrm{ppm}$ ) and the area of ring carbon signals between $100 \mathrm{ppm}$ and $60 \mathrm{ppm}$. The DS of commercial diacetate and triacetate cellulose samples were 2.31 and 2.97 , respectively.

The DS of the $\mathrm{CN}$ membranes was not calculated by NMR and in this work we will use the 2.2 value measured by Berthumeyrie et al. [15] using quantitative elemental analysis $(11.76 \% \mathrm{~N})$. Work is currently in progress to synthesize $\mathrm{CN}$ with different degrees of substitution. In future work, these polymers will be used to prepare calibration curves that will be compared with the ones discussed here. They will be also used to optimize an NMR method for an accurate determination of DS values in CN samples.

\section{Cellulose nitrate calibration curves}

The infrared spectra of cellulose nitrate obtained by $\mu$ FTIR and FTIR-ATR are plotted in Fig. 1. At time 0, both spectra are characterized by the stretching of the $\mathrm{CH}$ and $\mathrm{CH}_{2}$ bonds between 2900 and $3000 \mathrm{~cm}^{-1}$; the strong nitrate vibration bands ( $\mu$ FTIR: 1653,1280 and $840 \mathrm{~cm}^{-1}$;
ATR-FTIR: 1636, 1274 and $827 \mathrm{~cm}^{-1}$ ); the cellulosic vibrational envelope between 1200 and $900 \mathrm{~cm}^{-1}$ [31]. A decrease in DS leads to a decrease of the nitrate groups absorbance and an increase of the hydroxyl band (3700 $-3000 \mathrm{~cm}^{-1}$ ), evolving towards the spectrum of cellulose, Fig. 1.

The main plasticizer of celluloid in heritage studies is camphor, and its influence must be assessed before the selection of the reference and probe peaks. Its infrared spectrum is characterized by the strong carbonyl stretching at $1743 \mathrm{~cm}^{-1}$ and low-intensity bands between 1200 and $900 \mathrm{~cm}^{-1}$, Fig. 2 . However, in celluloid, the carbonyl band is shifted to lower wavenumbers $\left(1731 \mathrm{~cm}^{-1}\right)$ as a result of hydrogen bonding and does not overlap with the nitrate asymmetric stretching vibration $\left(v_{\mathrm{a}} \mathrm{NO}_{2}\right)$ at $1662 \mathrm{~cm}^{-1}$, Fig. 2. Furthermore, the influence of the plasticizer between 1200 and $900 \mathrm{~cm}^{-1}$ is residual to none.

Taking these data into account, we tested for reference peaks the $\mathrm{COC}$ and the $\mathrm{C}=\mathrm{O}$ stretching bands. Our experimental data suggest that the best results were obtained using the first. For this reason, the COC 

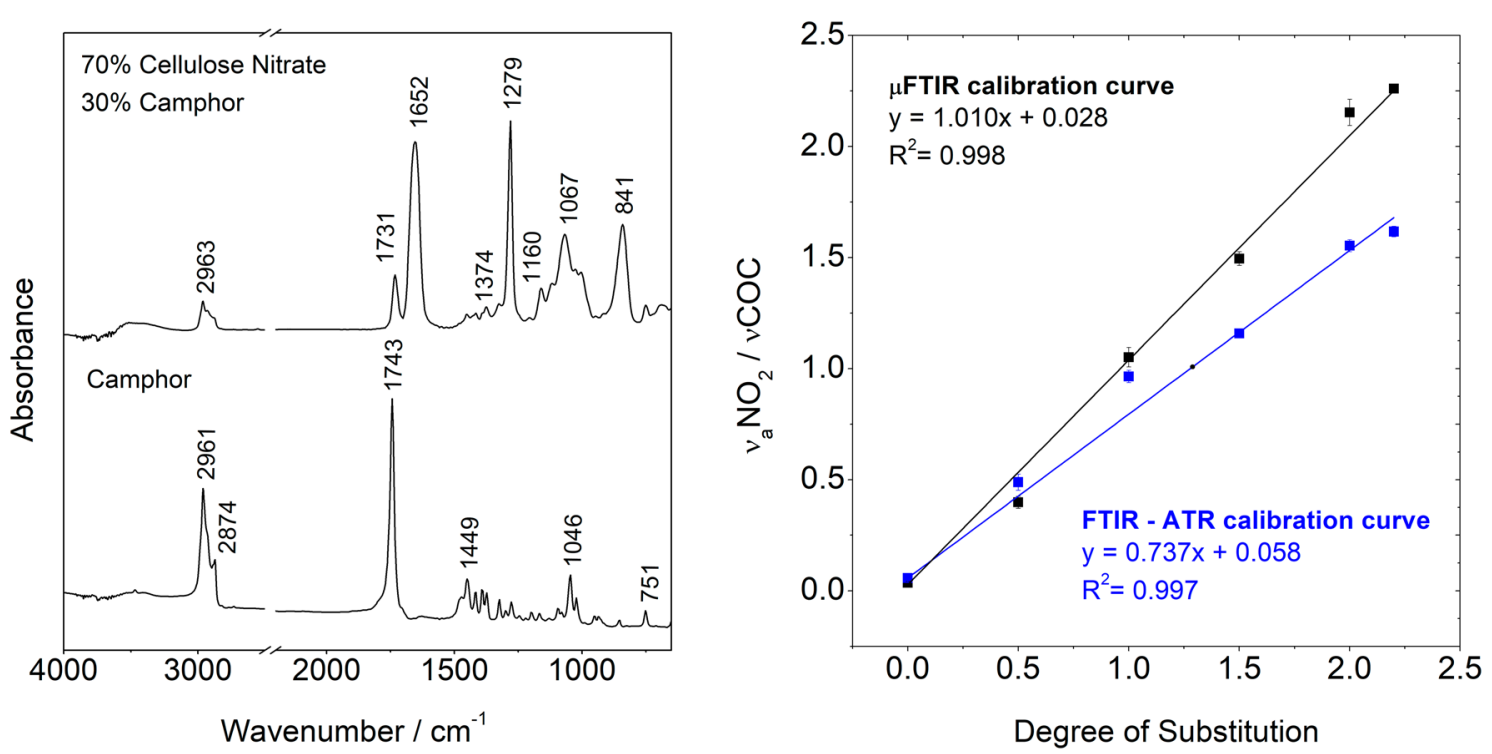

Fig. 2 Infrared spectra of a celluloid reference and camphor left. DS linear calibration curves for $\mu$ FTIR and ATR-FTIR and respective equations and coefficients of determination $\left(R^{2}\right)$, right. For more details, see the text

stretching ( $\mu$ FTIR: $1070 \mathrm{~cm}^{-1}$; ATR-FTIR: $1060 \mathrm{~cm}^{-1}$ ) was selected as the reference peak for the determination of the DS, and the hydroxyl and the nitrate groups bands can be used as probe peaks. For this work $v_{\mathrm{a}} \mathrm{NO}_{2}$ was selected and in Fig. 2, the ratio $v_{\mathrm{a}} \mathrm{NO}_{2} / \mathrm{vCOC}$ is plotted as a function of DS, resulting in calibration curves with high coefficients of determination ( $\mu$ FTIR: $R^{2}=0.998$; ATRFTIR: $\left.R^{2}=0.997\right)$.

\section{Measuring the degree of substitution in cellulose nitrate cinematographic films and correlating it with their conservation condition}

The obtained DS calibration curves were next applied to historical cinematographic films. The values calculated for NEMOSINE films ranged from 1.71 to 2.20 for $\mu$ FTIR and from 1.76 to 1.93 for FTIR-ATR, Table 2. Comparing the $\mu$ FTIR and FTIR-ATR results it is possible to observe that samples 50508 and DIF 50500 correlate well. In the other samples (50509, S4, S5 and S6), the values calculated by ATR-FTIR are lower, with differences ranging from 0.26 to 0.33 . A possible explanation is related to the fact that at the surface the polymers are more degraded than in the bulk. In that case, when using ATR-FTIR we only measure the DS at the surface, whereas with $\mu$ FTIR both bulk and surface are analyzed in a $\mu$ sample. To understand the reason for these differences, in future work, it will be necessary to make a $\mu$ sampling profiling to assess if DS changes from the surface to the bulk. Spectra and images of the cinematographic films are presented as Additional file 1: Table S2 and Figure S5.
Film S5 presents the closer match to a pristine film $(\mathrm{DS}=2.26)$, Table 2 . The lower values obtained for the other historical cinematographic films reflect the molecular aging of the $\mathrm{CN}$ support. The values of DS and hardness were close for films 50509, S4, S5, which have images in good conservation conditions. In comparison, for films DIF 50500, 50508 and S6, the calculated DS values did not correlate with the image condition: DIF 50500 presents a readable image and presented the lowest DS value (1.71). On the other hand, films 50508 and S6 presented DS values similar to films 50509, S4 and 55 but their image is in poor condition, see Table 2 and Additional file 1: Table S2. These results show that

\begin{tabular}{|c|c|c|c|}
\hline Sample & $\begin{array}{l}\text { DS } \\
\mu \mathrm{FTIR}\end{array}$ & $\begin{array}{l}\text { DS } \\
\text { FTIR-ATR }\end{array}$ & $\begin{array}{l}\text { Hardness } \\
\text { (Shore A) }\end{array}$ \\
\hline DIF 50500 & 1.71 & 1.76 & $95 \pm 0.80$ \\
\hline 50508 & 1.86 & 1.85 & $96 \pm 0.63$ \\
\hline S6 & 2.06 & 1.80 & $96 \pm 0.75$ \\
\hline S4 & 2.15 & 1.89 & $96 \pm 1.10$ \\
\hline 50509 & 2.18 & 1.85 & $97 \pm 1.02$ \\
\hline S5 & 2.20 & 1.93 & $97 \pm 1.17$ \\
\hline Original DS & 2.26 & 2.26 & - \\
\hline
\end{tabular}

For more details, see text

a See Table 1 

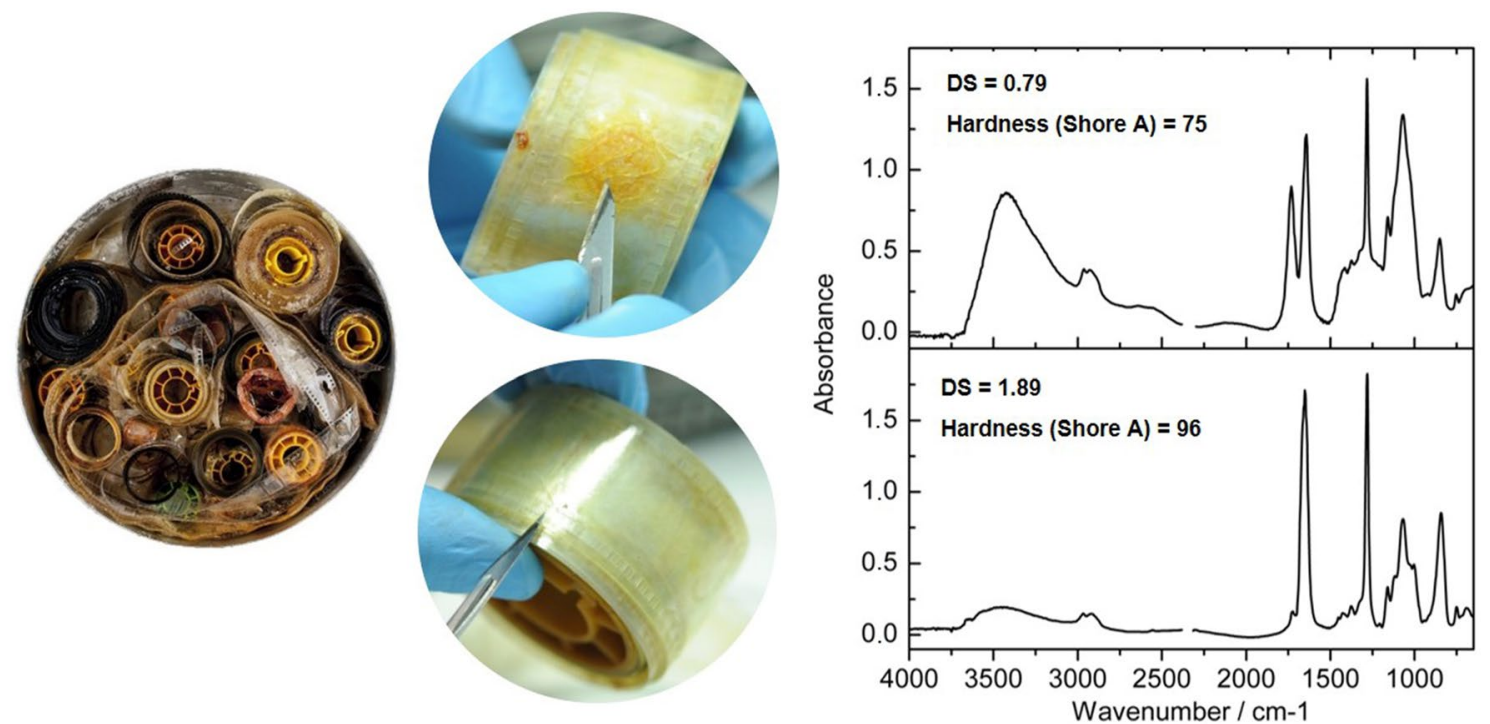

Fig. $3 \mu$ FTIR analysis a cellulose nitrate reel (ANIM): an area of the reel which retains its elasticity has a calculated DS 1.89 and hardness (Shore A) $96 \pm 1.02$ and an area cracked and brittle presents DS 0.79 and hardness (Shore A) $75 \pm 1.67$

image degradation does not depend only on the degradation of the support, in this case, cellulose nitrate.

To assess the extent of degradation in a cinematographic reel from the outside to the inside, the $\mu$ FTIR calibration curve was also applied to a degraded reel from ANIM collection. The cellulose nitrate reel, kept in an aluminum box, was analyzed in two different areas: one exterior area that retains its elasticity, and an interior area extremely brittle, Fig. 3. The calculated DS 1.89 and 0.79 correlate well with the measured hardness (Shore A) $96 \pm 1.02$ and $75 \pm 1.67$, respectively, Table 2 . Thus, it was possible to correlate the molecular evolution, through the decrease in the DS values (reflecting the loss of the nitrate groups, with the formation of the pair $\mathrm{HNO}_{2} / \mathrm{HNO}_{3}$ that promotes main chain scission), with the observed physical alteration of cellulose nitrate: lower hardness and brittle film. The higher degradation observed in the inner film winding may be due to the accumulation of acids, not so easily off-gassing as in the outer parts.

NEMOSINE cinematographic films studied presented hardness values like the less degraded zone of the ANIM reel, existing a high correlation of DS and hardness with sample 50508. The DS and hardness calculated for the interior area of the ANIM reel is in accordance with the hardness decrease observed with the decrease of the DS in the NEMOSINE films, Table 2. These results point out the potentiality of DS quantification as an early warning tool for this polymer.

\section{Cellulose acetate calibration curves}

$\mu F T I R$ and ATR-FTIR spectra of cellulose acetate, at time 0 , are shown in Fig. 4. They are characterized by the carbonyl stretching $\left(\mu\right.$ FTIR $1751 \mathrm{~cm}^{-1}$; ATR-FTIR $\left.1734 \mathrm{~cm}^{-1}\right)$, the ester stretching ( $\mu$ FTIR $1235 \mathrm{~cm}^{-1}$; ATR-FTIR $\left.1212 \mathrm{~cm}^{-1}\right)$ and the methyl bending ( $\mu$ FTIR $1370 \mathrm{~cm}^{-1}$; ATR-FTIR $1368 \mathrm{~cm}^{-1}$ ); the stretching of the ether groups ( $\mu$ FTIR $1050 \mathrm{~cm}^{-1}$; ATR-FTIR $1030 \mathrm{~cm}^{-1}$ ); and the hydroxyl stretching (with maxima found at $\mu$ FTIR $3350 \mathrm{~cm}^{-1}$; ATR-FTIR $3330 \mathrm{~cm}^{-1}$ ) [32].

The main plasticizers for cellulose acetate-diethyl phthalate (DEP) and triphenyl phosphate (TPP)-display strong absorptions due to the phthalate ester groups (1727 and $1282 \mathrm{~cm}^{-1}$ ) that exclude the use of the acetate groups as probe or reference bands. In the historical samples selected for study, triphenyl phosphate was found as the main plasticizer, and the phosphate POC stretching $\left(960 \mathrm{~cm}^{-1}\right)$ does not overlap the $\mathrm{vCOC}$ reference band, Fig. 5.

Following a similar reasoning as for cellulose nitrate and considering the experimental evidence above described, $\mathrm{COC}$ and $\mathrm{C}=\mathrm{O}$ stretching bands were tested for reference peaks. Our experimental results show that using the first, higher linear correlation coefficients were obtained $\left(R^{2} \approx 0.7\right.$ versus $\left.>0.9\right)$, enabling a more accurate determination of DS (with the reference samples). Thus, cellulose acetate $\mathrm{COC}$ stretching was used as the reference peak for the ratio applied for the determination of the DS, Fig. 4. The probe bands to be considered are the ones influenced by hydrolysis, namely the hydroxyl and 


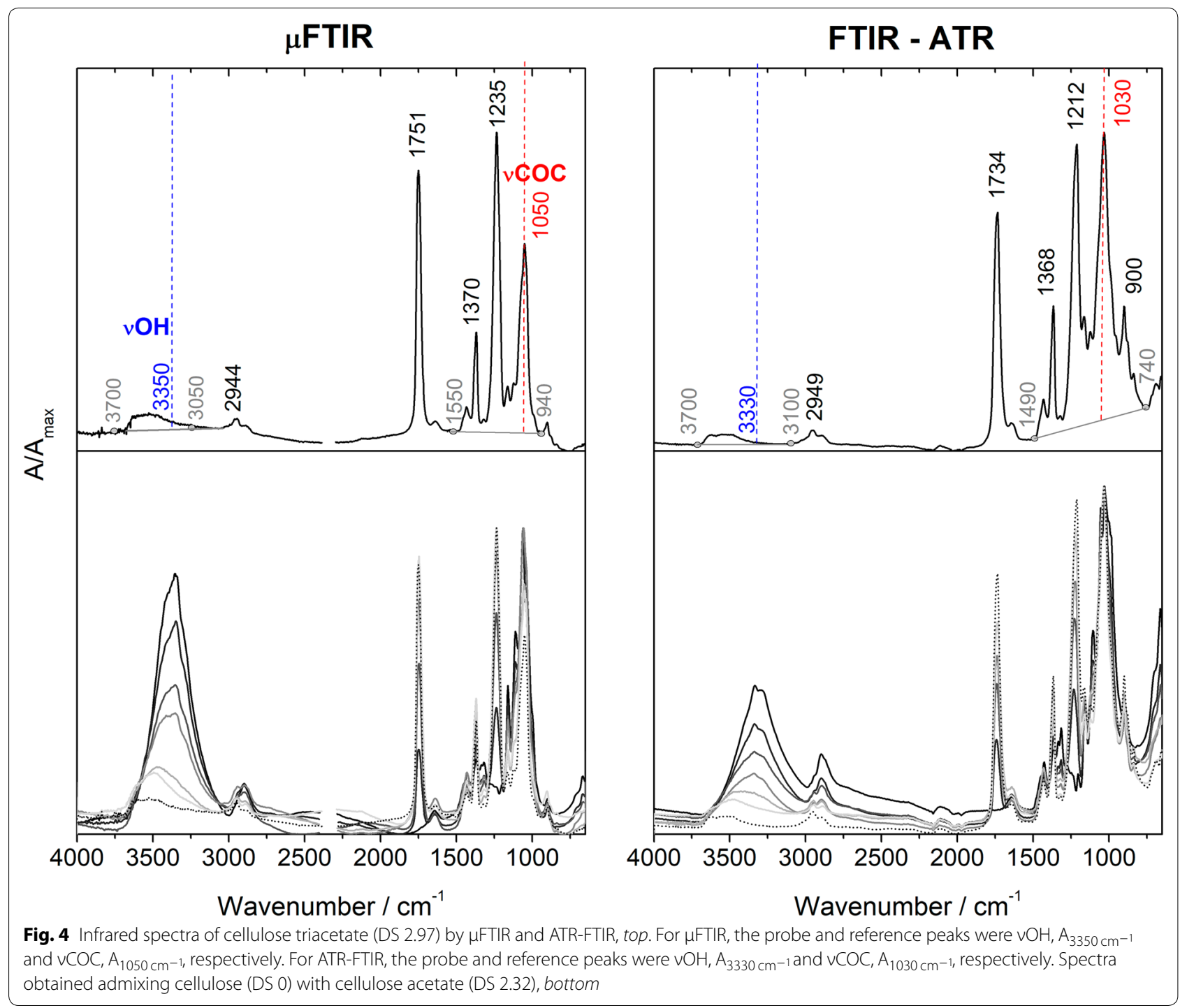

the ester bands. For this reason, the hydroxyl stretching ( $\mu$ FTIR $3350 \mathrm{~cm}^{-1}$; ATR-FTIR $3330 \mathrm{~cm}^{-1}$ ) was selected in this work as the probe peak. For the $\mathrm{vCOC} / \mathrm{vOH}$ ratio as a function of DS, a linear fitting was tested; however as observed by Fei et al. a quadratic polynomial fitting had higher coefficients of determination $\left(\mathrm{R}^{2}\right)$. Thus, the quadratic equations were chosen for the calculation of the DS in the case studies, Table 3.

\section{Measuring the degree of substitution in cellulose acetate cultural heritage and correlating it with their conservation condition \\ Application in cinematographic and photographic films}

Films from the San Payo collection, previously evaluated as in good conservation state by Roldão [30], were analyzed to assess if it is possible to propose an "original" DS for cellulose acetate in these photographic collections. All samples presented the typical spectrum of a TPP and DEP plasticized cellulose acetate, Fig. 5 and Additional file 1: Figures S6 and S7. According to the literature, a commercialized diacetate film's DS falls between 2.2 and 2.5 and a triacetate film between 2.9 and 3, Table 1. The DS of the San Payo samples ranged from 2.5 to 2.83, Table 4. Having been assessed as in good condition, these results suggest that samples SP 548 (DS 2.50) and SP 544 (DS 2.53) were produced as diacetate films. We propose the use of the cellulose triacetate DS interval 2.9-3 as the "original" DS for the samples that presented values ranging from DS 2.69 to 2.83 . The lower DS in relation to the "original" DS is indicative of degradation.

The extent of degradation in a cinematographic reel was also studied from the outside to the inside, Table 5. 

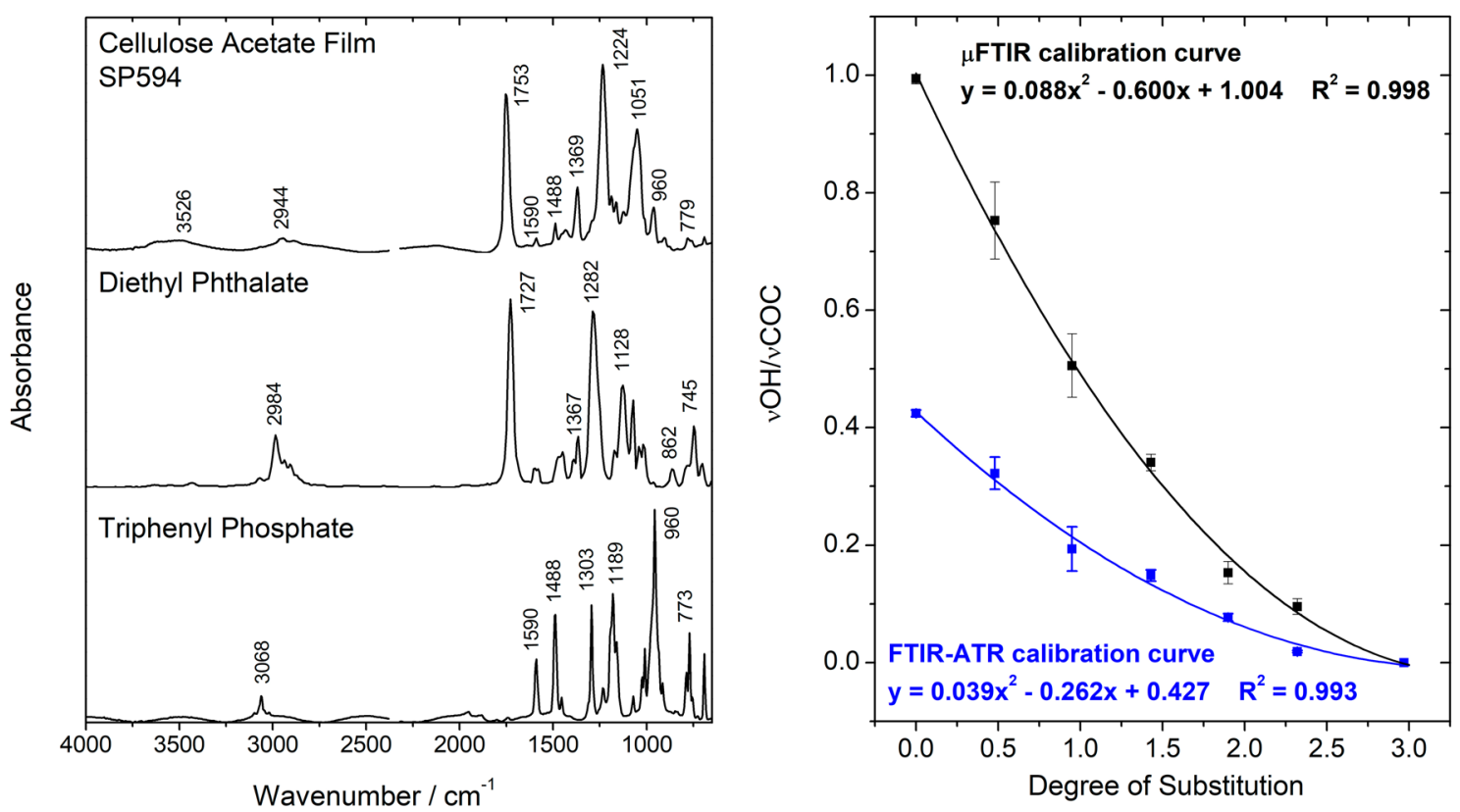

Fig. 5 Infrared spectrum of a historical cellulose acetate film from the San Payo collection (SP594), plasticized with triphenyl phosphate and diethyl phthalate. The spectra of the two plasticizers are shown for comparison, left. DS calibration curves and respective equations and coefficients of determination $\left(\mathrm{R}^{2}\right)$ for the polynomial fitting of the $\mathrm{VOH} / \mathrm{VCOC}$ ratios calculated from $\mu$-FTIR and ATR-FTIR, right

Table 3 DS calibration curves obtained by applying polynomial (2nd degree) and linear regressions

\begin{tabular}{|c|c|c|c|c|}
\hline \multirow[t]{2}{*}{ Analytical method } & \multicolumn{2}{|l|}{ Polynomial fitting } & \multicolumn{2}{|l|}{ Linear fitting } \\
\hline & Equation & $R^{2}$ & Equation & $R^{2}$ \\
\hline 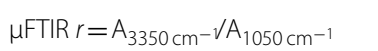 & $r=0.088 \mathrm{DS}^{2}-0.600 \mathrm{DS}+1.004$ & 0.998 & $r=-0.341 D S+0.896$ & 0.948 \\
\hline ATR-FTIR $r=A_{3330 \mathrm{~cm}^{-}} / A_{1030 \mathrm{~cm}^{-1}}$ & $r=0.039 \mathrm{DS}^{2}-0.262 \mathrm{DS}+0.427$ & 0.993 & $r=-0.146 \mathrm{DS}+0.379$ & 0.940 \\
\hline
\end{tabular}

Table 4 DS calculated through the calibration curve ( $\mu \mathrm{FTIR})$

\begin{tabular}{llllllllll}
\hline Sample & SP 548 & SP 544 & SP 594 & SP 324 & SP 543 & SP 542 & SP 593 & SP 592 & SP 600 \\
\hline DS ( $\mu$ FTIR) & 2.50 & 2.53 & 2.69 & 2.74 & 2.74 & 2.76 & 2.80 & 2.82 & 2.83 \\
\hline
\end{tabular}

The predicted pristine value for CDA and CTA are 2.2-2.5 and 2.9-3, respectively

The reel studied, SCS0057, is dated from 1950 to 1960. In this decade, the more stable cellulose triacetate was already being commercialized. The values obtained with both spectroscopy techniques ranged from 1.39 to 0.83 ( $\mu$ FTIR) and 1.36 to 0.76 (ATR-FTIR). These values agree with the poor conservation condition of the film, which emits an intense vinegar odor. The results show that cellulose acetate degradation is more severe in the inner parts of the reel where the cellulose acetate is covered from both sides due to film winding, as was observed for $\mathrm{CN}$ reels. Possibly, in these parts, the release of the degradation products is more difficult, and the accumulation of acetic acid formed promotes a faster film's deterioration. The $\mu$ FTIR and ATR-FTIR results correlated well, the outer sample having DS values 1.39 and 1.36, respectively, and the inner samples 0.85 and 0.79 , respectively. Samples taken from 0.9 and $1.8 \mathrm{~cm}$, considering 0 the outer turn in a total of $8.5 \mathrm{~cm}$, presented higher DS values for $\mu$ FTIR in comparison with ATR-FTIR, Table 5. As proposed for historical cellulose nitrate films, this difference may be due to a higher degradation at the film surface compared to the bulk. Spectra of the samples are presented in Additional file 1: Figure S8. Considering the 
Table 5 DS of cellulose acetate historical reel SCS0057, calculated on samples by $\mu$ FTIR and ATR-FTIR

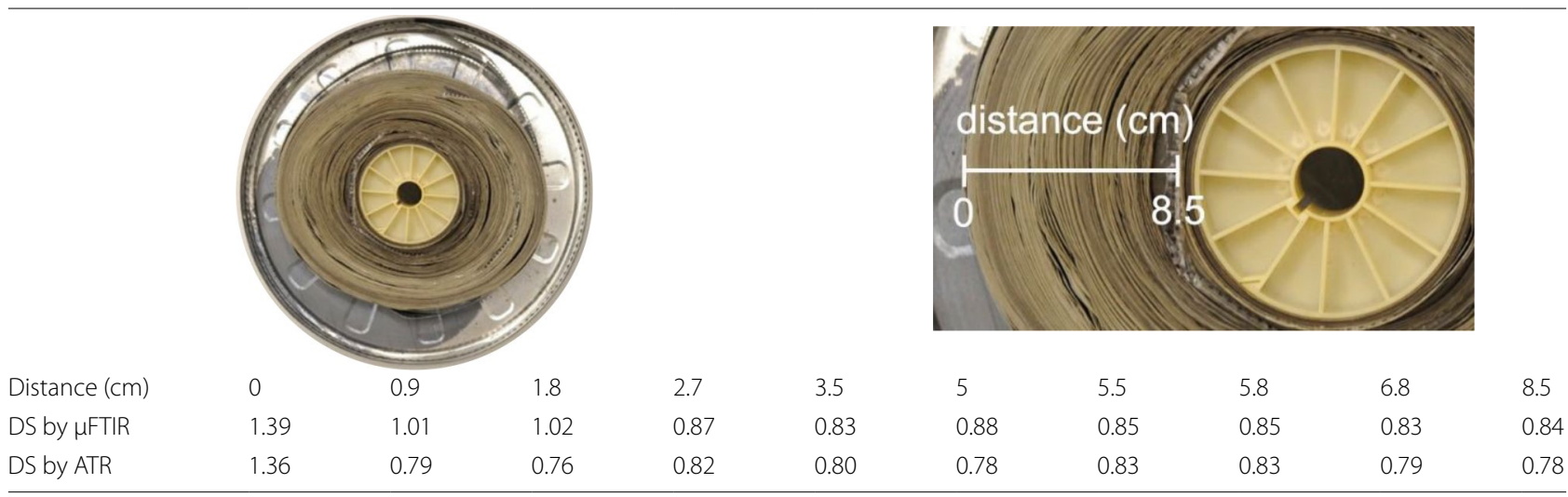

The sampling distances $(\mathrm{cm})$ start from the outer turn

high level of degradation observed, it will be difficult to predict its original value.

\section{Application in works of art made solely of cellulose acetate} Cellulose nitrate in sheets was used in three Portuguese artworks dated from the 1960s, by the artist José Escada, Fig. 6. One of the works made by this artist is in good conservation condition (Dans la plage), and the two others are in an advanced stage of degradation (La fête and Relief Orange). The DS calculation, Fig. 6, correlated with the visual assessment of the conservation condition of the artworks: La fête presented the lower DS average value of 1.86 and Dans la plage presented the higher DS of 2.11. Considering the values presented for injection molding in Table 2, we propose the "original" DS range of the cellulose acetate sheets that compose the artworks from 2.2 to 2.3. It is important to note that the comparison between the three artworks becomes possible since they are from the same period and the plastic material was possibly purchased at the same store in Paris (Micap) according to the artist Lourdes Castro, which was a friend of José Escada [33].

\section{Conclusions}

In heritage collections, cellulose nitrate and acetate objects can start irreversible deterioration without any visible warning signals. Their degradation poses a threat to other materials as very reactive chemicals are released such as $\mathrm{HNO}_{2}, \mathrm{HNO}_{3}$, and $\mathrm{CH}_{3} \mathrm{COOH}$. In major museums and archives, it is possible to control the damage posed by these chemicals, but it is not possible to prevent their degradation. However, in other institutions with fewer resources, a centenary cultural heritage may be stored in inappropriate conditions, becoming increasingly devalued, degraded and at risk of total loss. To develop innovative and sustainable preservation conditions, in a first phase, it is fundamental to correlate the molecular degradation with the physical deterioration, in order to develop early warning systems. The latter will allow professionals to make informed decisions on when it will be necessary to preserve an artwork in cold storage. This work contributes to this endeavour. For the first time, the extent of degradation was measured in historical samples through calibration curves previously optimized in reference samples. ATR-FTIR and $\mu$ FTIR calibration curves were applied in situ and in micro-samples, respectively, in photographic and cinematographic films as well as in contemporary works of art made with cellulose acetate sheets. It was possible to clearly distinguish very good and poor conservation conditions, at the molecular level, and to correlate it with a preliminary visual assessment and with hardness. In future work, the quantification of the extent of hydrolysis that was developed in this work will be integrated in multi-scale models, coupled with sensors to monitor specific volatiles, to prevent objects to reach an irreversible degradation path. This will create a breakthrough in the way collections based on cellulose derivatives are preserved, allowing the safeguard of citizens' memories by preserving documents and photographs in centennial voluntary associations and other non-profit organizations, with innovative and affordable solutions.

Work is currently in progress, to apply this tool extensively in dated films to systematically determine original degrees of substitution in historical collections. It will be also applied to follow the accelerated ageing of highly characterized historical films to provide insight into their molecular evolution. 


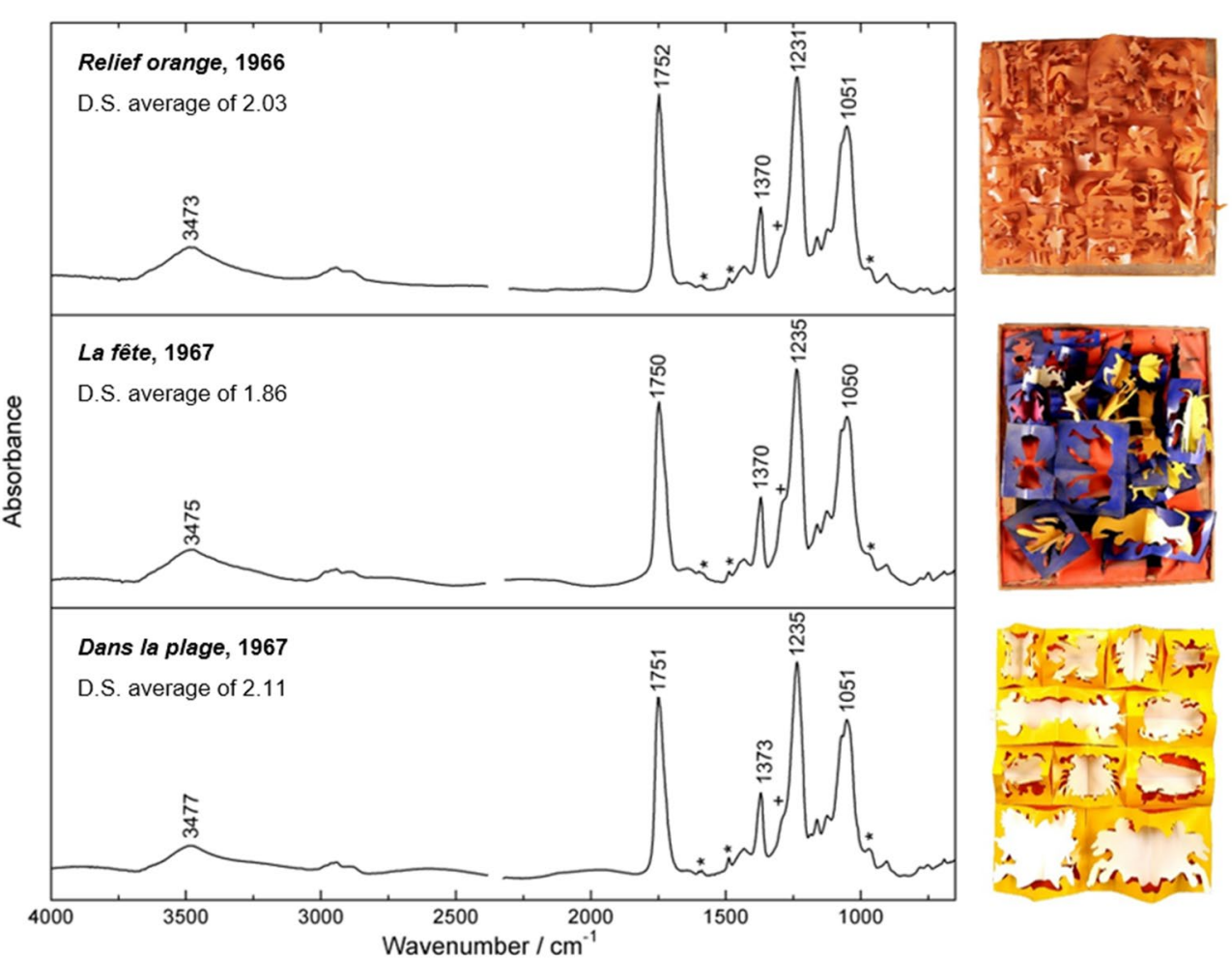

Fig. 6 Infrared spectra of an orange module from Relief orange (1966), a blue module from La fête (1967) and a yellow module from Dans la plage (1968). The plasticizers triphenyl phosphate $(*)$ and diethyl phthalate $(+)$ are identified

\section{Supplementary information}

Supplementary information accompanies this paper at https://doi. org/10.1186/s40494-020-00373-4.

Additional file 1. Supporting information.

\section{Abbreviations}

ANIM: National Archive of Motion Pictures; ATR-FTIR: Attenuated Total Reflection-Fourier Transform Infrared Spectroscopy; CA: Cellulose acetate; CDA: Cellulose diacetate; CN: Cellulose nitrate; CTA: Cellulose triacetate; DEP: Diethyl phthalate; DS: Degree of substitution; DFF: Deutsches Filminstitut \& Filmmuseum; MCC: Micro crystalline cellulose; NMR: Nuclear magnetic resonance spectroscopy; OEAW: Phonogrammarchiv of the Vienna Academy of Sciences; TPP: Triphenyl phosphate; $\mu F T I R$ : Micro Fourier Transform Infrared Spectroscopy; $v$ : Stretching ( $v_{a}$ : asymmetric stretching).

\section{Acknowledgements}

The generous support and kindness of Maria Arlete Alves da Silva, director of GALERIA 111 was invaluable in many aspects, and it will be difficult to truly acknowledge her importance in this research. Sara Babo is gratefully acknowledged for sharing her expertise on the conservation of the works by José Escada. We thank João Lopes for his longtime support and fruitful discussions. We would also like to thank Erich R. Schmid and Josef Bailer, both consultants of the Phonogrammarchiv, Austrian Academy of Sciences.

\section{Authors' contributions}

MJM, AMR, NW and AN contributed with the conception and design of the research work; MJM, AMR, EMA, SN, FR, AN, ER, and AAA with the acquisition, analysis and interpretation of data. MJM with SN, FR, EMA and AN were responsible for the quantification of DS by infrared spectroscopy. NW and ER contributed with the selection of the historical samples. EMA and SN studied the two artworks by José Escada (La fête and Relief orange). MJM, AR and SN prepared the first version of this paper. AAA was responsible for the NMR experiments and for the calculation of the DS in cellulose acetate samples by NMR. All authors read and approved the final manuscript.

\section{Funding}

This work has received funding from the European Union's Horizon 2020 Research and Innovation Programme (H2020-NMBP-35-2017), grant agreement no 76081, Project NEMOSINE, "Innovative packaging solutions for storage and conservation of 20th century cultural heritage of artefacts based on cellulose derivatives; and Fundação para a Ciência e a Tecnologia, Ministério da Ciência Tecnologia e Ensino Superior (FCT/MCTES), Portugal, through doctoral programme CORES-PD/00253/2012, PB/BD/114412/2016, PD/BD/136678/2018 doctoral grant; and Associated Laboratory for Sustainable Chemistry - Clean Processes and Technologies - LAQV REQUIMTE which is financed by FCT/ MCTES (UID/QUI/50006/2019). AAA is grateful for the post-doctoral fellowship from Fundación Alfonso Martín Escudero.

\section{Availability of data and materials}

All data generated or analyzed during this study are included in this published article (and its additional file).

\section{Competing interests}

The authors declare that they have no competing interests.

\section{Author details}

${ }_{1}^{1}$ REQUIMTE-Laboratório Associado para a Química Verde, Departamento de Química e Departamento de Conservação e Restauro, Faculdade de Ciências e Tecnologia, Universidade NOVA de Lisboa, 2829-516 Caparica, Portugal. 2 Department of Chemistry "G. Ciamician", University of Bologna, Ravenna Campus, Via Guaccimanni 42, 48123 Ravenna, Italy. ${ }^{3}$ PhonogrammarchivAustrian Academy of Sciences, Liebiggasse 5, 1010 Vienna, Austria. 
Received: 2 December 2019 Accepted: 16 March 2020

Published online: 06 April 2020

\section{References}

1. Edge M, Allen NS, Jewitt TS, Horie CV. Fundamental aspects of the degradation of cellulose triacetate base cinematograph film. Polym Degrad Stab. 1989;25:345-62

2. Edge M, Allen NS, Jewitt TS, Horie CV. The inhibition of oxidative and hydrolytic degradation pathways in archival cellulose-triacetate base cinematograph films. Polym Degrad Stab. 1990;29:31-48.

3. Edge M, Allen NS, Williams DAR, Thompson F, Horie V. Methods for predictive stability testing of archival polymers: a preliminary assessment of cellulose triacetate based motion picture film. Polym Degrad Stab. 1992;35:147-55

4. Edge M, Allen NS, Hayes M, Riley PNK, Horie CV, Luc-Gardette J. Mechanisms of deterioration in cellulose nitrate base archival cinematograph film. Eur Polym J. 1990;26:623-30.

5. Ahmad IR, Cane D, Townsend JH, Triana C, Mazzei L, Curran K. Are we overestimating the permanence of cellulose triacetate cinematographic films? A mathematical model for the vinegar syndrome. Polym Degrad Stab. 2020;172:109050.

6. Ciliberto E, Gemmellaro P, lannuso V, La Delfa S, Urso RG, Viscuso E. Characterization and weathering of motion-picture films with support of cellulose nitrate, cellulose acetate and polyester Who. Procedia Chem. 2013;8:175-84.

7. Fei P, Liao L, Cheng B, Song J. Quantitative analysis of cellulose acetate with a high degree of substitution by FTIR and its application. Anal Methods. 2017;9:6194-201.

8. Friedel R. Pioneer plastic: the making and selling of celluloid. Madison: The University of Wisconsin Press; 1983.

9. Rahman M, Brazel CS. The plasticizer market: an assessment of traditional plasticizers and research trends to meet new challenges. Prog Polym Sci. 2004:29:1223-48

10. Richardson E, Giachet MT, Schilling M, Learner T. Assessing the physical stability of archival cellulose acetate films by monitoring plasticizer loss. Polym Degrad Stab. 2014;107:231-6.

11. Yarsley VE, Flavell W, Adamson PS, Perkins NG. Cellulosic plastics. London: The Plastics Institute; 1964.

12. Giachet MT, Schilling M, Mccormick K, Mazurek J, Richardson E, Khanjian $\mathrm{H}$, et al. Assessment of the composition and condition of animation cels made from cellulose acetate. Polym Degrad Stab. 2014;107:223-30.

13. Thérias S, Bussière P, Gardette M, Gardette J, Lattuati-derieux A, Universite C, et al. Altération des objets en celluloïd dans les collections: étude des mécanismes de vieillissement Degradation of celluloid in art works: a study of the mechanisms. Actes du Colloq Sci des matériaux du Patrim Cult. 2012;2:68-73.

14. Bussiere PO, Gardette JL, Therias S. Photodegradation of celluloid used in museum artifacts. Polym Degrad Stab. 2014;107:246-54.

15. Berthumeyrie S, Collin S, Bussiere PO, Therias S. Photooxidation of cellulose nitrate: new insights into degradation mechanisms. J Hazard Mater. 2014;272:137-47.

16. Allen NS, Edge M, Appleyard JH, Jewitt TS, Rorie CV. The degradation and stabilization of historic cellulose acetate/nitrate base motion-picture film. J Photogr Sci. 1988;36:103-6.

17. Allen NS, Edge M, Francis D, Horie CV, Appleyard TH, Tewitt TS. The nature of the degradation of archival cellulose-ester base motion-picture film: the case for stabilization. J Photogr Sci. 1988;36:34-9.

18. Quye A, Littlejohn D, Pethrick RA, Stewart RA. Accelerated ageing to study the degradation of cellulose nitrate museum artefacts. Polym Degrad Stab. 2011;96:1934-9.

19. Rychly J, Lattuati-Derieux A, Matisova-Rychla L, Csomorova K, Janigova I, Lavedrine B. Degradation of aged nitrocellulose investigated by thermal analysis and chemiluminescence. J Therm Anal Calorim. 2012;107:1267-76.

20. Hamrang A. Degradation and stabilzation of cellulose based plastics \& artifacts. Ph.D. Thesis. Faculty of Science and Engineering, The Manchester Metropolitan University; 1994.

21. Hon DNS, Gui TL. Photodegradation of cellulose nitrate. Polym Photochem. 1986;7:299-310.

22. Atkins PW, Jones L. Chemistry: molecules, matter and change. 3rd ed. New York: W H Freeman \& Co; 1997.

23. Littlejohn D, Pethrick RA, Quye A, Ballany JM. Investigation of the degradation of cellulose acetate museum artefacts. Polym Degrad Stab. 2013;98:416-24.

24. Puls J, Wilson SA, Hölter D. Degradation of cellulose acetate-based materials: a review. J Polym Environ. 2011;19:152-65.

25. Hon NS. Photodegradation of cellulose acetate fibers. J Polym Sci Polym Chem Ed. 1977;15:725-44.

26. Merlin A, Fouassier J-P. Photochemical investigations into cellulosic materials, IV. Die Angew Makromol Chemie. 1982;108:185-95.

27. Hosono K, Kanazawa A, Mori H, Endo T. Enhanced degradation of cellulose acetate film containing diphenyliodonium salt-benzophenone. Cellulose. 2007;14:529-37.

28. Samios E, Dart RK. Preparation, characterization and biodegradation studies on cellulose acetates with varying degrees of substitution. Polymer. 1997;38:3045-54.

29. Kono $\mathrm{H}$, Hashimoto $\mathrm{H}$, Shimizu Y. NMR characterization of cellulose acetate: chemical shift assignments, substituent effects, and chemical shift additivity. Carbohydr Polym. 2015;118:91-100.

30. Roldão É. A contribution for the preservation of cellulose esters black and white negatives. Ph.D. Thesis. NOVA School of Science and Technology, Universidade NOVA de Lisboa; 2018.

31. Neves A, Angelin EM, Roldão É, Melo MJ. New insights into the degradation mechanism of cellulose nitrate in cinematographic films by Raman microscopy. J Raman Spectrosc. 2018:50:202-12.

32. Ilharco LM, De Barros RB. Aggregation of pseudo isocyanine iodide in cellulose acetate films: structural characterization by FTIR. Langmuir. 2000:20:9331-7.

33. Babo S. Estudo e Conservação da obra Dans La Plage de José Escada: a degradação do acetato de celulose e o tratamento de deformações em materiais termoplásticos. BSc Report. NOVA School of Science and Technology; 2006

34. Stewart RA. Analytical studies of the degradation of cellulose nitrate artefacts. Ph.D. Thesis. University of Strathclyde; 1997.

35. Mazurek J, Laganà A, Dion V, Etyemez S, Carta C, Schilling MR. Investigation of cellulose nitrate and cellulose acetate plastics in museum collections using ion chromatography and size exclusion chromatography. J Cult Herit. 2019;35:263-70.

\section{Publisher's Note}

Springer Nature remains neutral with regard to jurisdictional claims in published maps and institutional affiliations.

\section{Submit your manuscript to a SpringerOpen ${ }^{\oplus}$ journal and benefit from:}

- Convenient online submission

- Rigorous peer review

- Open access: articles freely available online

- High visibility within the field

Retaining the copyright to your article

Submit your next manuscript at springeropen.com 